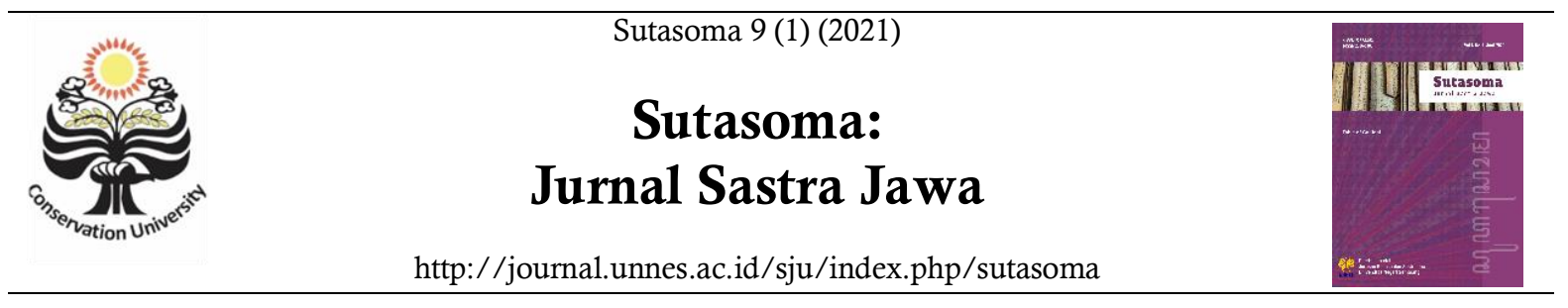

\title{
Sêrat Bayanolah: Naskah Jawa sebagai Sarana Pelurusan Penyimpangan Akidah Islam Karya Raden Panji Natarata
}

\author{
Mila Indah Rahmawati ${ }^{1}$, Wakit Abdullah Rais ${ }^{2}$, dan Prasetyo Adi Wisnu Wibowo ${ }^{3}$ \\ ${ }^{1}$ Linguistik Deskriptif, Fakultas Ilmu Budaya, Universitas Sebelas Maret, Indonesia \\ ${ }^{2.3}$ Program Studi Sastra Daerah, Fakultas Ilmu Budaya, Universitas Sebelas Maret \\ Corresponding Author: milaindahr_38@student.uns.ac.id.
}

DOI: $10.15294 /$ sutasoma.v9i1.40855

Accepted: September 14 2020 Revison: June 29th 2021 Published: June $28^{\text {th }} 2021$

\begin{abstract}
Abstrak
Karya sastra Jawa dianggap sebagai karya sastra yang bermutu tinggi. Hal tersebut erat kaitannya dengan nilainilai luhur yang terkandung di dalamnya. Ajaran atau nilai-nilai luhur dalam karya sastra Jawa ini bisa disebut dengan istilah karya sastra piwulang, yaitu karya yang bersumber dari nilai-nilai keagamaan atau ajaran yang berasal dari Tuhan. Salah satu karya sastra Jawa yang bernuansa piwulang ini adalah Sêrat Bayanolah. Karya ini mengisahkan tentang perjalanan seorang panatagama Keraton Yogyakarta dalam menenemukan hakikat kehidupan yang sejati. Untuk memahami konsep ini tidak mudah karena realitasnya banyak aliran pemikiran dan keagamaan menyimpang yang justru dapat menggelincirkan manusia dari jalan yang benar. Penelitian ini dilakukan secara deskriptif kualitatif. Sumber data yang digunakan adalah Sêrat Bayanolah Karya Raden Panji Natarata yang dikoleksi oleh Yayasan Sastra Lestari Surakarta. Berdasarkan hasil penelitian ditemukan bahwa hakikat manusia sebagai makhluk tidak sama dengan hakikat Allah (Tuhan) sebagai Pencipta. Di samping itu, dalam memaknai konsep kehidupan dan kematian harus disesuaikan dengan ajaran-ajaran Islam karena pada kenyataannya masih ada para ulama maupun orang berilmu yang masih salah dalam memahami konsep kehidupan dan kematian tersebut.
\end{abstract}

Kata Kunci: Sêrat Bayanolah, naskah Jawa, penyimpangan, akidah

\begin{abstract}
Javanese literary works are considered as high-quality literary works. This is closely related to the noble values contained in Javanese literary works. The teachings or noble values in this Javanese literary work are usually referred to as piwulang literary works, namely works that originate from religious values or teachings that come from God. One of the Javanese literary works with piwulang nuances is Serat Bayanolah. This work tells about the journey of a panatagama at the Yogyakarta Palace in discovering the true essence of life. To understand this concept is not easy because in reality there are many deviant schools of thought and religion which can derail people from the right path. This research was conducted in a descriptive qualitative manner. The data source used was Serat Bayanolah by Raden Panji Natarata, which was collected by the Museum of Reksa Pustaka Pura Mangkunegaran, Surakarta. Based on the research results, it was found that the essence of man as a creature is not the same as the essence of God $(G o d)$ as the Creator. Besides, interpreting the concept of life and death must be adjusted to Islamic teachings because in reality there are still scholars and knowledgeable people who still misunderstand the concept of life and death.
\end{abstract}

Keywords: Sêrat Bayanolah, Javanese script, deviations, faith

(C) 2021 Universitas Negeri Semarang

p-ISSN 2252-6307

e-ISSN 2686-5408 
Mila Indah Rahmawati, dkk/ Sutasoma 9 (1) (2021)

\section{PENDAHULUAN}

Karya sastra sebagai cerminan realitas kehidupan memiliki beberapa fungsi, salah satunya adalah sarana mensyiarkan agama. Melalui karya sastra, penyampaian dakwah agama menjadi indah, luwes, dan terkesan lebih toleran. Hal ini mampu mengakomodasi segi dakwah dengan budaya. Dengan demikian, objek dakwah, dalam hal ini yaitu masyarakat, akan lebih mudah menerima pesan-pesan dakwah yang disampaikan.

Salah satu karya sastra Jawa yang memuat esensi dakwah dalam nuansa lokal adalah Sêrat Bayanolah. Sêrat Bayanolah merupakan karya sastra piwulang yang mencakup ajaran-ajaran luhur terkait dengan nilai-nilai agama (religiusitas), falsafah (kebenaran atau logika yang mendalam), etika (kebaikan), dan estetika (keindahan) (E1 Firdausy, 2017:102). Sêrat Bayanolah ini berbentuk tembang macapat yang sudah disalin secara turun-menurun dengan jenis tulisan berupa manuskrip Jawa. Bahkan, sudah pernah diterbitkan dalam almanak Jawa H. Buning di Yogyakarta dengan sangkala rasaning kawula asalira Gusti.

Sêrat Bayanolah ini ditulis oleh Raden Panji Natarata. Beliau adalah orang yang pernah menjabat sebagai kepala distrik di Ngijon, Yogyakarta yang juga memiliki nama lain yaitu Raden Sasrawijaya. Bayanolah berarti 'penerangan yang menunjukkan adanya Allah'. Secara umum, Sêrat Bayanolah ini berisi tentang kisah Raden Panji Natarata saat proses pencarian hakikat kehidupan melalui para guru yang pernah ditemuinya. Raden Panji Natarata berguru kepada para pemuka agama di Pulau Jawa, mulai dari Banten sampai dengan Banyuwangi.

Selain sebagai seorang yang berasal asli dari Yogyakarta, Raden Panji Natarata juga seorang panatagama (ulama yang mendukung raja) di lingkup Kasultanan Yogyakarta (Rubaidi, 2019:24). Oleh sebab itu, pola berpikir Raden Panji Natarata tidak terlepas dari nilai dasar atau ruh Keraton Yogyakarta yang bernapaskan Islami. Hal tersebut sejalan dengan upaya meneguhkan jati diri budaya masyarakat Yogyakarta, yaitu dengan berlandaskan pada nilai-nilai dasar ajaran Islam (Rahman \& Hodayah, 2011:52).

Adapun selama dalam pengembaraannya, Raden Panji Natarata mendapatkan ajaran-ajaran dari pemuka agama yang bertentangan dengan konsep dasar Islam. Kondisi tersebut dapat menimbulkan bahaya, yaitu terjadinya pemahaman yang salah dan menyimpang dari kebenaran kalam-kalam Ilahi. Berdasarkan latar belakang tersebut, Raden Panji Natarata mencoba untuk meluruskan konsep keilahian, terutama dari perspektif agama Islam.

Hal pertama yang perlu ditekankan dalam pelurusan konsep keilahian ini adalah akidah. Konsep akidah secara umum dapat dimaknai peng-Esa-an terhadap Allah SWT sebagai satu-satunya Illah (Tuhan) yang layak disembah. Hal ini biasa disebut dengan istilah tauhid. Pembentukan konsepsi dasar tauhid ini sangat penting ditanamkan pada masingmasing individu, terutama kaum muslim. 
Mila Indah Rahmawati, dkk/ Sutasoma 9 (1) (2021)

Ketauhidan merupakan jalan utama bagi manusia agar dapat memahami kedudukannya sebagai hamba Allah SWT. Dengan kata lain, seseorang harus menyadari bahwa dirinya adalah hasil dari ciptaan Tuhan. Pada titik inilah manusia kehilangan wewenang sehingga tidak bisa berbuat sekehendak hati (Saputro, 2016:279).

Usaha penamaan nilai-nilai ketauhidan ini oleh Raden Panji Natarata direpresentasikan melalui sarana têmbang macapat. Sarana ini dipilih karena masing-masing têmbang macapat memiliki karakteristik sehingga cocok untuk menyampaikan suatu pesan, nasihat, dan ujaran dakwah sesuai dengan kebutuhan yang diperlukan (Susanto, 2016:301). Bagi orang yang sudah memeluk agama Islam, cara tersebut dapat memberikan suatu pemahaman dan pencerahan yang benar tentang menjalankan Islam dengan lebih bermartabat. Di sisi lain, masyarakat yang masih berpaham animisme, dinamisme, pemeluk agama Hindu, serta Budha diharapkan dapat tertarik mempelajari agama Islam dan tergerak hatinya untuk memeluk agama Islam (Sahal, 2015:208).

Adapun untuk menemukan perbedaan atau novelty dengan penelitian yang sudah pernah ada, peneliti juga menyertakan kajian pustaka terkait penelitian tentang ajaran ketauhidan maupun korelasi têmbang macapat sebagai sarana dakwah. Utomo (2007) pernah melakukan penelitian tentang konsepsi tasawuf yang dicanangkan oleh Raden Ngabehi Ranggawarsita dalam beberapa karya sastra yang diciptakannya. Hasil penelitian menunjukkan bahwa secara umum ajaran tasawuf dalam beberapa karya Raden Ngabehi Ranggawarsita meliputi konsep tentang manusia, konsep tentang Tuhan, jalan kelepasan, dan kelepasan. Konsepsi tentang manusia dibahas dalam Sêrat Salokajiwa. Berdasarkan hasil penelitian Utomo, R. Ng. Ranggawarsita menyebutkan bahwa konsepsi manusia berkaitan erat dengan perihal penciptaannya (2007:35). Menurut R. Ng. Ranggawarsita, Tuhan pertama kali menciptakan manusia melalui cahya nurokyat, yang di dalam ranah tasawuf lebih dikenal dengan istilah nur Muhammad atau hakikat Muhammad (Simuh, 1988:288). Selain itu, R. Ng. Ranggawarsita juga menyampaikan bahwa manusia terdiri atas empat unsur, yaitu jasad, nafsu, napas, dan roh. Keempat unsur tersebut berkelindan dengan anasir pembentuk manusia, yaitu bumi, api, angin, dan air (Utomo, 2007:38).

Adapun konsepsi tentang Tuhan dipaparkan R. Ng. Ranggawarsita dalam Wirid Maklumat Jati. Dalam karya sastra tersebut dinyatakan bahwa sebelum adanya alam semesta ini, Allah sudah lebih dahulu ada sebagai Dzat mutlak yang bersifat tunggal dan abadi. Lebih lanjut, konsepsi tentang Tuhan juga diuraikan R. Ng. Ranggawarsita dalam Serat Wirid Hidayat Jati, yakni dengan menguraikan keberadaan Tuhan yang hanya dapat dimengerti oleh akal, bukan dengan pancaindra. Kemudian dalam Sêrat Salokajiwa konsepsi Tuhan diungkapkan dengan istilah wus nir kinaya ngapa 'tidak dapat digambarkan seperti apa' sehingga Tuhan hanya bisa digambarkan oleh manusia melalui simbol 
Mila Indah Rahmawati, dkk/ Sutasoma 9 (1) (2021)

(Utomo, 2007:39). Sementara itu, pada konspesi jalan kelepasan diuraikan adanya empat tingkatan yang perlu ditempuh secara sempurna agar manusia dapat menuju kepada Tuhannya. Empat tingkatan yang dimaksud ialah syariat, tarikat, hakikat, dan makrifat dan dituliskan R. Ng. Ranggawarsita dalam Sêrat Wirid Hidayat Jati. Lebih lanjut, perihal konsepsi tentang kelepasan berhubungan dengan terjadinya wihdatul wujud (bersatunya manusia dengan Tuhan) atau yang sering disebut dengan manunggaling kawula-Gusti, sebagaimana yang diungkapkan $\mathrm{R}$. Ng. Ranggawarsita dalam Sêrat Kalatidha, Sêrat Pranawa Jati, Sêrat Sabda Jati, dan Sêrat Cênthini.

Penelitian sejenis lainnya, yaitu penelitian yang dilakukan oleh Saddhono \& Pramestuti (2018), mengungkapkan bahwa têmbang macapat dapat menjadi suatu bentuk harmonisasi antara nilai-nilai keagamaan dan kearifan lokal. Salah satu bentuk harmonisasi yang dimaksud ialah melalui têmbang macapat diuraikan tahap-tahap perjalanan manusia, mulai dari kelahiran manusia sampai dengan kematiannya. Maka dari itu, hal ini sangat berkaitan dengan ranah ontologi, epistemologi, dan aksiologi yang dikemas secara filosofis dalam karya sastra Jawa berbasis kearifan lokal, yakni têmbang macapat. Berdasarkan penelitiannya, Saddhono \& Pramestuti menyebutkan bahwa nilai-nilai kegamaan berasal dari kepercayaan manusia kepada Tuhan. Secara spesifik, mereka juga memilih têmbang Pucung sebagai objek penelitian karena dalam têmbang Pucung tersebut terdapat nilai keagamaan tentang pandangan kehidupan akhir manusia, yakni ketika kematian mendatanginya Nilai-nilai keagamaan yang terkandung pada têmbang Pucung dapat dieksaminasikan, baik secara leksikal maupun filosofis. Oleh karena itu, dapat disimpulkan bahwa nilai-nilai keagamaan tersebut dapat memotivasi manusia untuk selalu dekat dengan Sang Pencipta pada setiap jenjang atau fase perjalanan hidupnya, terutama dibuktikan dengan perilaku yang senantiasa taat dalam koridor nilai-nilai keagamaan (2018:25).

Merujuk pada kedua penelitian Utomo (2007) dan Saddhono \& Pramestuti (2018) tersebut, posisi penelitian ini pada dasarnya memiliki tema yang sama, yakni membahas perihal aspek filosofis dan religiositas perjalanan hidup manusia dalam bentuk têmbang macapat. Namun demikian, penelitian ini lebih berfokus terhadap pelurusan ajaran yang diterima oleh Raden Panji Natarata ketika mengembara untuk berguru tentang hakikat penciptaan hingga kematian manusia. Hemat peneliti, pentingnya dilakukan penelitian ini bertujuan untuk memperjelas atau meluruskan ajaran-ajaran yang dikemas dengan ungkapanungkapan indah, tetapi justru menyesatkan. Lazimnya orang akan tertarik dan terkesima dengan indah dan manisnya kata-kata dalam têmbang macapat sehingga terkadang orang tidak menyadari atas tipu daya dari suatu permainan bahasa. Oleh karena itu, peneliti akan mengungkap pesan-pesan dakwah Raden Panji Natarata dalam Sêrat Bayanolah sebagai upaya beliau dalam meluruskan pemahaman manusia terkait ajaran akidah yang semestinya. 
Mila Indah Rahmawati, dkk/ Sutasoma 9 (1) (2021)

$\begin{array}{crrr}\text { Hal } & \text { tersebut } & \text { diperkuat } & \text { dengan } \\ \text { pendapat } & \text { Soehadha } & (2016: 30) & \text { yang }\end{array}$ memaparkan bahwa aktualisasi konsep tauhid dalam hubungannya dengan sinergitas budaya lokal hendaknya tidak mudah kagum dan terkesima dengan hal-hal baru. Hal ini memberikan penekanan agar dalam setiap tindakan manusia perlu berhati-hati dan bersikap selektif, meneliti, dan mempertimbangkan secara cermat. Dengan demikian, segala informasi yang datang dan diterima tidak serta-merta dianggap sebagai kebenaran.

Di samping itu, perbedaan penelitian ini dengan penelitian sebelumnya terletak pada sumber datanya. Naskah-naskah Jawa pada penelitian sebelumnya merupakan naskahnaskah koleksi dari Kasunanan Surakarta, sedangkan naskah Sêrat Bayanolah ini berbasis Kasultanan Yogyakarta. Kenyataan tersebut tidak terlepas dari sejarah panjang Kasultanan Yogyakarta sebagai salah satu Kerajaan Mataram Islam Jawa terkemuka di Nusantara. Dengan demikian, pendapat Raden Panji Natarata kemungkinan besar berlandaskan nilai-nilai keislaman yang kuat sehingga penelitian ini diharapkan dapat digunakan sebagai upaya preventif agar dalam praktiknya masyarakat tidak terjebak ajaran-ajaran menyimpang, baik di rentang waktu saat karya ini ditulis maupun saat sekarang.

\section{METODE PENELITIAN}

Jenis penelitian yang digunakan dalam penelitian ini adalah deskriptif kualitatif. Sumber data diperoleh dari manuskrip Jawa klasik berjudul Serat Bayanolah dengan nomor katalog 129 yang merupakan koleksi Yayasan Sastra Lestari, Surakarta. Atas dasar menjaga efektivitas dan efisiensi penelitian, sumber data yang digunakan merupakan naskah yang sudah dialihaksarakan dan dikaji secara filologis oleh Yayasan Sastra Lestari (Natarata, 2010). Pertimbangan peneliti memanfaatkan kajian filologis dari Yayasan Sastra Lestari Surakarta dengan pertimbangan yayasan tersebut merupakan lembaga yang sudah diakui untuk mempreservasi naskah-naskah kuno sehingga dimungkinkan kajian filologis yang sudah dilakukan bersih dari kesalahan (kesalahannya sangat kecil). Adapun sumber data pendukung terkait dengan studi kepustakaan penelitian ini meliputi buku, bacaan, dan artikel yang membahas tentang nilai-nilai ketauhidan, khususnya yang berhubungan dengan karya sastra Jawa yang membahas perihal ajaran ketauhidan.

Sehubungan dengan hal tersebut, peneliti memanfaatkan teori analisis wacana, yang berdasarkan bentuknya penelitian termasuk wacana puisi, dalam hal ini puisi Jawa tradisional (têmbang macapat). Adapun dari segi cara dan tujuan pemaparannya, data dalam penelitian ini tergolong wacana narasi atau penceritaan. Hal itu terkait dengan datadata yang ditampilkan dalam penelitian ini menceritakan fase-fase kehidupan manusia, mulai dari proses penciptaan sampai dengan kematiannya. Sesuai dengan bentuk têmbang yang tersusun atas klausa-klausa, penelitian ini menggunakan metode agih atau distribusional (Sudaryanto, 1993:15-16). Dengan demikian, 
Mila Indah Rahmawati, dkk/ Sutasoma 9 (1) (2021)

untuk memahami makna teks, proses analisis data dilakukan melalui interpretasi langsung terhadap isi naskah dan penarikan simpulan berdasarkan apa yang tercantum di dalamnya. Artinya, peneliti menguraikan tiap-tiap kata, frasa, klausa, ataupun satu sampai beberapa bait têmbang untuk menginterpretasikan pemaknaan teks secara utuh sehingga pesan yang ingin disampaikan oleh pengarang akan dapat dipahami dengan baik oleh pembaca.

\section{HASIL DAN PEMBAHASAN}

Pemahaman dan pengenalan terhadap Tuhan dapat dilakukan melalui dua cara, yaitu dengan penyelidikan akal pikiran dan dengan merasakan atau menyaksikan melalui mata hati (Suteja 2016:17). Proses mengenal Tuhan dapat dilakukan dengan cara menghayati asal-usul, perjalanan hidup, dan tujuan hidup manusia. Namun demikian, pada kenyatannya perjalanan untuk mengenal Tuhan bukanlah sesuatu yang mudah. Manusia harus memiliki tekad yang kuat untuk selalu mencari. Selain itu, pemurnian akidah juga diperlukan agar bisa waspada terhadap berbagai aliran atau paham menyimpang yang justru akan menggiring manusia dalam kesesatan.

Dalam Sêrat Bayanolah ini, Raden Panji Natarata berusaha meluruskan penyimpanganpenyimpangan akidah yang ia dapatkan dari beberapa guru, sarjana, maupun ulama yang ternyata tidak sesuai dengan ajaran Islam.

Adapun secara teknis, peneliti menampilkan data-data yang berupa kata, frasa, klausa, ataupun bait têmbang kemudian memberikan keterangan penomoran data setelah teks têmbang. Secara lebih rinci, misalnya DH-1/B1, berarti huruf DH mengacu pada dua huruf terdepan metrum têmbang, dalam hal ini têmbang dhandhanggula, tanda hubung (-) menunjukkan penghubung metrum têmbang dengan penunjuk pupuh ke berapa, angka "1" menunjukkan bahwa têmbang yang dimaksud berada pada pupuh pertama, tanda garis miring (/) berfungsi memisahkan keterangan pupuh dan bait, huruf "B" menunjukkan bait, dan angka setelah huruf $\mathrm{B}$ menunjukkan letak bait yang dimaksud pada data, dalam contoh ini mengacu pada bait ke satu.

\section{a. Penyimpangan Pemahaman Terhadap Wujud Allah}

Saat awal perjalanannya mencari tahu hakikat Tuhan, Raden Panji Natarata menerima ajaran dari seorang ulama yang mengatakan bahwa Tuhan itu berwujud semacam cahaya yang mengagumkan. Hal tersebut sebagaimana diungkapkan dalam têmbang dhandhanggula pada data (1) berikut.

(1) Kang gumêbyar-gêbyar angêbati/ linêbonan dèn anggêp sawarga/nèng kono Gusti pamore/lah iku wong kaliru/wus kadhadhung ginawèng jajil/sawènèh malah ana/wruh cahya umancur/dinalih sipating Allah/iya iku kumpuling kawula Gusti/têtêp wong kabegalan// (DH-1/B9)

'Yang memancarkan cahaya dan mengagumkan/dimasuki dan dianggap surga/di situlah dianggap sebagai tempat Tuhan/keyakinan yang seperti itu merupakan 
Mila Indah Rahmawati, dkk/ Sutasoma 9 (1) (2021)

pemikiran yang keliru/karena sudah terpengaruh dengan setan ijajil/yang lainnya pun ada yang/melihat cahaya yang memancar/dikiranya itu adalah Allah/itulah yang disebut menyatunya hamba dengan Tuhannya/hal itu juga masih tetap tertipu'.

Berdasarkan data (1), klausa wruh cahya umancur/dinalih sipating Allah 'melihat cahaya yang memancar/dikiranya itu adalah Allah' merupakan pendapat perihal wujud Tuhan dari seorang ulama yang ditemui Raden Panji Natarata. Melalui klausa tersebut Sang Ulama menyampaikan bahwa Allah berwujud cahaya yang terang. Akan tetapi, pendapat tersebut tidak berdasar sehingga secara lembut Raden Panji Natarata meluruskan pemahaman pembaca agar tidak mudah percaya jika Allah sebagai Tuhan berwujud seperti cahaya yang bersinar. Adapun nasihat Raden Panji Natarata serta pelurusan pemahaman dinyatakan pada data (2), yaitu melalui pupuh dhandhanggula bait ketiga belas.

(2) Prayogene kawruhana becik/kayadene angen-angenira/Mukhammad darma sapangreh/Rasul rasaning manusa/ kabeh saka Hagyaning pikir/nanging dudu Pangeran/ing sajaninipun/kang saweneh pra pukaha/ingaranan tanpa kantha tanpa kanthi/tan gatra tan satmata (DH-1/B13)

'Sebaiknya pahamilah dengan baik/bagaikan angan-angan dirimu/jasad diri sebatas sebagai tempat/yang disebut Rasul rasa dari diri manusia/semua atas kekuasaan pikiran/namun hal itu bukan Tuhan/yang sesungguhnya/ada juga para fukaha (Ahli hukum Agama)/Dia tanpa asal tanpa teman/tidak berbentuk dan tidak terlihat'

Dalam teks di (2), Raden Panji Natarata menyampaikan nasihatnya bahwa sebaiknya manusia dapat mengendalikan angan-angan dirinya dalam hal memahami wujud Tuhan. Jasad diri merupakan sesuatu yang berwujud sehingga bisa dilihat dan diraba. Oleh karena itu, jasad diri yang dimaksud dalam konteks ini bukanlah wujud Tuhan yang sesungguhnya. Hal ini dikarenakan jasad diri tersebut adalah tempat di mana ruh atau jiwa manusia bersemayam dan bersifat materiel, sedangkan Tuhan adalah Dzat Yang Menciptakan dan bersifat nonmateriel.

Secara keilmuan konvensional, memang sangat sulit untuk membuktikan bahwa Tuhan (Allah) bersifat nonmateriel. Akan tetapi, merujuk pada pendapat Al Kindi, seorang filsuf muslim pertama, ia mengatakan bahwa Tuhan bukanlah benda dan tidak dapat disifati dengan apapun yang ada di dalam pikiran makhluk (Zainuddin, 2013). Pendapat tersebut sesuai dengan apa yang sudah termaktub di dalam beberapa ayat Al-Qur'an dan hadits yang terkait dengan larangan berpikir Dzat Allah. Yang sesungguhnya perlu dipikirkan adalah berbagi penciptaan dan nikmat-nikmat Allah. Hal itu sudah cukup menjadi bukti bahwa Tuhan (Allah) itu ada 
Mila Indah Rahmawati, dkk/ Sutasoma 9 (1) (2021)

sebagaimana seperti yang terdapat dalam QS. Ali Imran ayat 191 (Kemenag RI, 2016:75).

Selain itu, menurut peneliti klausa ingaranan tanpa kantha tanpa kanthi/tan gatra tan satmata 'Dia tanpa asal tanpa teman/tidak berbentuk dan tidak terlihat' menegaskan bahwa Allah ada tanpa asal dan tanpa teman, maksud dari tanpa asal dan tanpa teman adalah Allah ada tanpa ada yang menciptakan dan tanpa ada yang menyamai. Allah juga tidak berbentuk dan tidak terlihat. Hal ini sesuai dengan falsafah Jawa yang berbunyi tan kêna kinira, tan kinaya ngapa, yang sesuai dengan tafsir surat AlIkhlas ayat 3 yang menyatakan bahwa Tuhan (Allah) itu tidak beranak (tanpa teman/tidak beristri) dan tidak diperanakkan (tanpa asal/tidak dilahirkan). Artinya, Allah adalah Tuhan Yang Maha Esa dan Maha Kuasa atas segala sesuatu.

Raden Panji Natarata juga kembali menegaskan bahwa dengan kuasa-Nya Allah memiliki wewenang mutlak atas segalanya. Hal ini tecermin pada data (3) yang dikemas dalam pupuh dhandhanggula bait kedua puluh satu berikut.

(3) Gusti iku mirêng tanpa kuping/aningali datan mawi netra/tanpa prabot kuwasane/ngandika tanpa tutuk/lamun maksih nganggo piranti/têtêp dudu Pangeran Jroning Qur'an nutur/kuwasanira Pangeran// (DH1/B21)

'Tuhan itu mendengar tanpa menggunakan telinga/melihat tanpa mata/ tanpa alat dalam kekuasaannya/berfirman tanpa mulut/jika masih menggunakan alat/ tetap bukanlah Tuhan/Di dalam AlQur'an telah banyak disebutkan/tentang Maha Kuasa Tuhan'

Eksistensi Allah sebagai Tuhan sungguh jelas terlihat dalam sifat keesaan-Nya. Allah dapat mendengarkan pinta dan doa para makhluk-Nya tanpa harus menggunakan telinga. Begitu pula Allah dapat melihat segala tingkah dan perbuatan makhluk-Nya tanpa menggunakan mata. Kuasa Allah meliputi segalanya, baik yang ada di langit maupun yang ada di bumi. Oleh sebab itu, Allah tidak memerlukan alat dalam kekuasaan-Nya karena apapun yang masih bergantung menggunakan alat tetaplah bukan Tuhan.

Di sisi lain, untuk memberikan petunjuk kepada para hamba-Nya, firman Allah yang merupakan kalam-kalam IlahiahNya telah termaktub suci di dalam Al-Qur'an. Di Al-Qur'an pulalah Allah telah banyak menyebutkan kemahakuasaan dan kemahabesaran-Nya. Dengan demikian, sampai kapanpun dan dengan alat apapun angan-angan manusia tidak akan mampu membayangkan wujud Allah sebagai Tuhan.

Dalam pupuh Kinanthi bait keempat dan kelima disebutkan bahwa ada ulama yang mengaku melihat wujud Allah sebagai rupa yang agak bercahaya. Berikut petikan datanya.

(4) Sêjatine durung wêruh/ngawur kawoworan eblis/lawan malih asring ana/pra Ngulama ngaku wasis/ rukyatolahi yen Nendra/wruh ing rupanya pribadi// (KI-II/B4) 
Mila Indah Rahmawati, dkk/ Sutasoma 9 (1) (2021)

\begin{abstract}
'sesungguhnya belum paham/ sehingga semuanya bercampur dengan ilmu setan/yaitu saat para ulama yang mengaku ahli/dalam melihat Allah, sehingga ketika sedang bermimpi/akan melihat ujud diri'
\end{abstract}

Mawa praba smu umancur/lir wulan purnama sidhi/iku inganggep Pangeran/kang murba maseseng bumi/iku wong katunan ing tyas/luput panampaning dalil// (KI-II/B5)

'Dengan rupa agak bercahaya/ bagaikan bulan purnama/itu yang dianggap sebagai Tuhan/yang menguasai seluruh bumi/itu orang yang tertipu batinnya sendiri/ karana salah menafsirkan dalil'

Pada kutipan pupuh kinanthi bait keempat Raden Panji Natarata mengisahkan bahwa dirinya sempat diwejang oleh para ulama yang mengaku ahli sehingga ketika bermimpi dapat melihat wujud Allah. Menurut para ulama tersebut, Allah berwujud rupa yang agak bercahaya seperti pancaran cahaya bulan purnama, sebagaimana yang disebutkan dalam klausa mawa praba smu umancur/lir wulan purnama sidhi/iku inganggêp Pangèran/'dengan rupa agak bercahaya/bagaikan bulan purnama/ itu dianggap sebagai Tuhan' bait kelima. Hal itu sudah jelas salah dan mengindikasikan bahwa ulama tersebut kurang tepat dalam memahami dalil.

Jika dipikir secara logika, penglihatan manusia memiliki kemampuan yang terbatas, termasuk dalam menangkap cahaya yang sangat terang. Oleh karena itu, apa yang dikatakan para ulama tersebut terkesan tidak logis. Di sisi lain, di dalam Al-Qur'an juga tidak ada dalil yang menyebutkan bahwa wujud Allah berupa pancaran cahaya seperti saat bulan purnama.

Berdasarkan data-data yang mencerminkan adanya penyimpangan pemahaman terhadap wujud Allah tersebut, Raden Panji Natarata memberikan penegasan agar manusia sebagai makhluk Allah tidak perlu merisaukan bagaimana wujud Allah yang sebenarnya. Hal ini diungkapkan dalam pupuh asmaradana bait ketiga puluh tiga berikut.

(5) Nora susah sira kaki/takon jumenenge Allah/mung weruha kuwasane/kang kagadhuh marang siralgedhene tanpa sama/lembut tan kena jinumput/saking rungsiting sasmita// (AS-III/B33) 'Janganlah kau bertanya/tentang adanya Tuhan/pahami saja Maha kuasa-Nya/yang dianugerahkan kepada dirimu/besar tidak ada bandingnya/lembut tanpa bisa diambil/ibarat sangat rahasia diriNya'

Sebagai makhluk Allah, hal terpenting yang dapat dilakukan dalam memahami wujud Allah adalah dengan cara merasakan dan menghayati segala kuasa-Nya yang sudah dianugerahkan kepada para makhluk-Nya. Klausa nora susah sira kaki/takon jumênênge Allah/mung wêruha kuwasane/kagadhuh marang sira/ 'janganlah kau bertanya/tentang adanya Tuhan/pahami saja kuasa-Nya/yang dianugerahkan kepada dirimu' sudah menjadi bukti bahwa Allah adalah Tuhan Yang Maha 
Mila Indah Rahmawati, dkk/ Sutasoma 9 (1) (2021)

Agung dan Maha Besar. Seluruh alam semesta yang tergelar nyata ini adalah bukti kemahakuasaan dan kebesaran-Nya.

Sementara itu, larik lêmbut tan kêna jinumput/saking rungsiting/'lembut tanpa bisa diambil/ibaratnya sangat rahasia diri-Nya' berarti Allah adalah Tuhan Yang Maha Lembut sehingga para makhluk tidak akan pernah bisa menyentuh-Nya. Akan tetapi, kelembutan-Nya bisa dirasakan melalui segala nikmat yang Dia karuniakan kepada para makhluk-Nya. Oleh karena itu, manusia sebagai makhluk hanya perlu beriman kepada Allah tanpa meragukan maupun mempermasalahkan bagaimana hakikat wujudNya.

\section{b. Penyimpangan Pemahaman Konsep Asal Kehidupan Manusia}

Dalam pengembaraannya, Raden Panji Natarata juga mendapatkan ilmu tentang asalusul kehidupan manusia. Akan tetapi, ilmu tersebut tidak sesuai dengan apa yang telah Allah firmankan di dalam Al-Qur'an.

(6) Supaya wruh sangkaning ngaurip/kang saweneh guru amumulang/asale janma ginawe/nembelas wijinipun/mapatmapat ping pat sakawit/iku yekti dora/tan pisan tinemu/tandha saksi nora analana maneh saka wadi madi mani/manikem yen mangkana// (DHI/B5)

'Agar mengetahui asal hidup/maka ada guru yang mengajarkan bahwa/asal manusia terbuat dari/enam belas bagian/empatempat dikalikan empat itu

\begin{abstract}
asalnya/sungguh hal itu adalah bohong/dan sungguh tidak masuk akal/ada juga yang mengatakan berasal dari wadi (rahasia), madi, mani/mani demikian yang diterangkan'
\end{abstract}

Konsep asal kehidupan manusia mengindikasikan bahwa perjalanan hidup manusia di alam dunia pasti ada yang menciptakan. Dalam kutipan pupuh dhandhanggula bait kelima tersebut, Raden Panji Natarata mengisahkan bahwa ia diajari oleh seorang guru yang menyebut bahwa asal manusia terbuat dari enam belas bagian. Enam belas bagian yang dimaksud berasal dari bilangan empat dikalikan empat. Pendapat tersebut sangat ambigu dan tidak masuk akal. Sangat jelas jika pendapat guru tersebut adalah suatu kebohongan dan tidak berdasar.

Di samping itu, ada juga guru yang mengatakan bahwa manusia terjadi karena adanya rahasia (keintiman) yang menyebabkan keluarnya mazi dan mani. Pada dasarnya, hal ini sejalan dengan firman Allah dalam beberapa ayat Al-Qur'an yang menyebutkan bahwa asal muasal manusia dari nutfah (air mani) di antaranya dalam QS.A1-Kahfi ayat 10, QS. A1Hajj ayat 78, QS. Al-Mu'minun ayat 13-14, dan QS. Al-Fatir ayat 45 (Kemenag RI, 2016).

Akan tetapi, dalam hal ini Raden Panji Natarata lebih menekankan bahwa asal manusia bermula dari penciptaan Nabi Adam.

(7) Yêkti dudu ngadam kang miwiti/kale para manuswa wus nyata/saka ngadam pinangkane/marma sagung nak putu/parsudinên asalirèkil dadining 
Mila Indah Rahmawati, dkk/ Sutasoma 9 (1) (2021)

kanyatahan/ingkang tanpa tutur/saksi kodrating Pangeran/luwih bênêr brêsih titi tur lêstari/campuring kautaman/ (DH-I/B6)

'Tentunya bukan Adam yang mengawalinya/asal muasal manusia sesungguhnya sudah sangat jelas/berasal dari Adam itulah asalnya/sehingga wahai anak cucu/carilah asal dirimu/sampai menjadi pemahaman yang nyata/yang tidak ada uraian katakatanya/sebagai saksi kodrat Tuhan/itu lebih benar dan jelas/sebagai bukti bersatunya kebenaran dan keutamaan'

Raden Panji Natarata menegaskan bahwa asal-muasal manusia sudah sangat jelas. Memang seperti yang sudah kita ketahui, asal manusia berawal dari penciptaan Nabi Adam, tetapi hakikatnya bukan Nabi Adamlah yang mengawali. Hal itu disampaikan pengarang dalam larik yêkti dudu ngadam kang miwiti/kale para manuswa wus nyata/saka ngadam pinangkane/'tentunya bukan Adam yang mengawalinya/asal muasal manusia sesungguhnya sudah sangat jelas/berasal dari Adam itulah asalnya'. Jadi, Nabi Adam adalah manusia yang diciptakan pertama kali dengan status sebagai makhluk, sedangkan yang mengawali penciptaan adalah Sang Pencipta, yaitu Allah SWT.

Adapun terkait dengan maksud Allah menciptakan para makhluk-Nya tidak sertamerta tanpa tujuan. Oleh karena itu, sudah menjadi keniscayaan bahwa tujuannya adalah agar para makhluk beribadah kepada-Nya. Tujuan itu tidak lain adalah untuk menempuh perjalanan menuju kembalinya manusia kepada Dzat yang dulu telah menciptakannya. Pernyataan ini sesuai dengan kutipan pupuh kesebelas dalam têmbang bermetrum dhandhanggula pada bait keenam berikut.

(8) sidaning wong tumitah nèng bumi/urip iku jodhone palastra/sabên ri kalong nyawane/tan wêruh kantunipun/sapira yèn maksih taruni/tan pisan nyipta pêjah/wusnya praptèng sêpuh/sabên dina gung sumêlang/awit jisim anyar luwase mrêpêki/anggege pulang kandhang// (DH-XI/B2)

'kepastian orang yang hidup di dunia/hidup jodohnya mati/setiap hari berkuranglah umurnya/tidak mengetahui umurnya tinggal berapa/ketika masih muda/tidak akan memikirkan kematian/ketika sudah tua/tiap hari merasa khawatir/karena raga yang baru akan segera mendatanginya/untuk kembali ke tempat asalnya'

Sudah menjadi kepastian Allah bahwa segala di dunia ini berpasangan, seakan menyiratkan bahwa hanya Allah-lah yang Maha Tunggal dan Maha Esa. Klausa urip iku jodhone palastra 'hidup jodohnya mati' menjadi salah satu bukti yang tidak dapat dipungkiri bahwa adanya kehidupan selalu berdampingan dengan kematian. Urip iku jodhone palastra 'hidup jodohnya mati' juga mengandung pesan tersirat bahwa suatu awal pasti ada akhirnya, yang datang pasti akan kembali (pulang). Hal 
Mila Indah Rahmawati, dkk/ Sutasoma 9 (1) (2021)

tersebut semakin menguatkan bahwa hanya Allah-lah satu-satunya yang tidak berawal dan tidak berakhir dan Allah bersifat kekal.

Sementara itu, uraian tentang penyimpangan pemahaman terkait kematian disampaikan Raden Panji Natarata dalam subbab berikut.

\section{c. Penyimpangan Pemahaman Konsep Kematian}

Hakikat kematian merupakan persoalan yang menyentuh ranah ontologis dalam dimensi filsafat (Karim, 2015:24). Dalam memahami konsep kematian ini seringkali terjadi kesalahpahaman, bahkan terkadang kematian dianggap sebagai akhir dari segala kehidupan. Padahal sebaliknya, kematian adalah awal dari kehidupan yang hakiki.

Dalam pengembaraannya, Raden Panji Natarata mendapatkan ajaran tentang kematian, tetapi lagi-lagi tidak sesuai dengan konsep kematian dalam Islam. Adapun penyimpangan konsep kematian tersebut diuraikan dalam pupuh kelima, yaitu têmbang mêgatruh bait 1-3 berikut ini.

(9) Kang sawènèh ana Mukmin sung pituduh/ing ngelmu sampurnèng pati/kang patitis paranipun/nanging pralaya umanjing/sadat sêkarating maot//

Miwah puji tatkala nyarsa rinacut/nèng lawang sawiji-wiji/ana dhewe pujinipun/lah iku mukmin niwasi/tan yogi dipunpitados//

Iya iku wong pracaya marang wuwus/wuwus ingkang dakik-dakik/ rèhning sinalinan têmbung/wong Jawa kang durung uning/basa Ngarab dadi elok// (ME-V/B1-3)

'Ada juga seorang mukmin, yang memberi petunjuk/tentang ilmu mati yang sempurna/yang benar arahnya/ketika meninggal dunia/masuk ke dalam syahadat ketika menghadapi sakaratul maut' 'Dan dengan memuji ketika sedang dicabut nyawanya/ketika melewati pintu satu demi satu/dan tiap pintu ada sendiri-sendiri jenis doanya/itu adalah ajaran Mukmin yang menyesatkan/tidak akan membawa kepada keselamatan jika dipercaya' 'Itulah manusia yang hanya percaya kepada ucapan/ucapan yang tinggitinggi/karena ucapannya telah diganti (dengan bahasa Arab)/dan orang Jawa yang belum paham bahasa Arab/maka dianggapnya bahwa ucapan itu sangatlah hebat'

Menurut Raden Panji Natarata, konsep kematian seperti yang telah diutarakan oleh guru mukmin tersebut merupakan ajaran yang menyesatkan. Islam tidak menerangkan bahwa fase kematian harus melewati pintu satu demi satu dan dalam melewati setiap pintu ada doa yang berbeda-beda. Hal tersebut hanyalah suatu ilusi yang diada-adakan orang yang mengaku mukmin dengan diperindah menggunakan bahasa Arab agar orang Jawa yang masih awam memercayainya.

Kritik atas pemahaman tentang kematian diungkapkan Raden Panji Natarata dalam bait selanjutnya, yakni pupuh kelima 
Mila Indah Rahmawati, dkk/ Sutasoma 9 (1) (2021)

dalam têmbang mêgatruh bait keempat dan kelima berikut.

$$
\begin{aligned}
& \text { (10) Mêlok mêlik emêling cangkêm } \\
& \text { sinêngguh/nyataning kawruh kang } \\
& \text { luwih/saking cupêting panggayuh/ } \\
& \text { yayah kabêntur ing wangsit/wasita } \\
& \text { kawruh kang ngamong // } \\
& \text { Omong-omong tutur kang wus kalantur/ } \\
& \text { tur-tuturunan jaman wis/wiwisikaning } \\
& \text { pra guru/alam Buda tanpa saksi/têmah } \\
& \text { ngalingilalakon//(ME-V/B4-5) } \\
& \text { 'Begitu indah rangkaian kata yang } \\
& \text { diucapkan dikira/ilmu tingkat } \\
& \text { tinggi/karena kurangnya pemaham- } \\
& \text { an/sehingga percaya begitu saja } \\
& \text { karena menganggapnya sebagai } \\
& \text { isyarat/kata dari yang mengucapkan- } \\
& \text { nya' tidak ada } \\
& \text { 'Perkataan dan ucapannya sudah } \\
& \text { diolah/hanya meniru ucapan orang } \\
& \text { zaman dahulu/yaitu bisikan atau } \\
& \text { ajaran dari para guru/saat zaman } \\
& \text { Budha yang tida } \\
& \text { buktinya/sehingga mengaburkan hal } \\
& \text { yang sebenarnya' }
\end{aligned}
$$

Menurut Raden Panji Natarata, ajaranajaran tentang kematian yang dikemas dalam bahasa Arab tidak serta merta berarti ilmu tingkat tinggi. Kata-kata berlafalkan bahasa Arab tersebut pada dasarnya merupakan ajaran agama Budha yang tidak dapat dibuktikan kebenarannya. Dengan demikian, ajaran yang seyogyanya memberikan pencerahan yang benar tentang kematian justru dapat menggiring ke dalam pemahaman yang menyesatkan.
Di sisi lain, ada lagi seorang ulama yang mengklaim bahwa dirinya telah menguasai dan mengajarkan ilmu kematian yang benar. Adapun kutipan datanya adalah sebagai berikut.

(11) Kaelokaning ngagêlsang kang kalantur/ ana manèh ngulama di/ambaboni muruk kawruh/mruhkêln trap pati patitis/soroging wayangan tinon// Mahyèng wujud putih mawênès tur mulus/sarupa ingkang ndarbènil gumawang cahya ngunguwung/nèng ngawang-awang kaèksi/ginulung parèk wignyanjong//

Jajar linggih iku dên anggêp panutan/mring kamuksan kang patitis/titising tyas linalarut/kinarya gandhulan pati/manjingkên swarga kinaot// (ME-V/B6-8)

'Keanehan hidup yang melantur/ada lagi seorang ulama/menguasai dan mengajarkan ilmu/menjelaskan cara kematian yang benar/agar melihat bayang, itulah yang harus diikuti' 'Berupa wujud putih bersih dan mulus/mirip dengan dirinya/yang memancarkan cahaya berkilauan/melayang-layang di udara/ mendekati diri seseorang itu' 'Kemudian duduk di sebelahnya, itulah yang dianggap sebagai penuntun/sebagai cara kematian yang benar/ketepatan batin itu yang harus diturut/digunakan sebagai pedoman saat kematian/yang akan menunjukan jalan menuju surga' 
Mila Indah Rahmawati, dkk/ Sutasoma 9 (1) (2021)

Konsep kematian seperti yang telah diungkapkan ulama tersebut menurut Raden Panji Natarata adalah ajaran yang sesat. Raden Panji Natarata menilai bahwa sang ulama salah menafsirkan bagaimana hakikat kematian yang semestinya. Adanya bayangan wujud putih tersebut pada dasarnya adalah pengaruh kekuatan daya penglihatan. Pengaruh tersebut dapat mencipta apa saja dan memperlihatkan bentuk rupa yang aneh-aneh. Pada intinya hal itu muncul dari pusat batin sehingga apapun akan bisa terlihat.

Untuk menanggulangi penyebaran ajaran kesesatan terkait dengan konsep kematian ini, Raden Panji Natarata menegaskan bahwa pemahaman jalan kematian yang sesungguhnya adalah dengan jalan menemuinya. Hal ini disampaikan dalam kutipan têmbang mêgatruh bait kesembilan belas berikut.

(12) Yèn sujana nirdeya manrang pakewuh/guruning pati wong matil guruning urip wong idhup/adhêping kahanan jati/anane mêngku sapakon// (ME-V/B19)

'Jika seseorang telah memahami yang sebenarnya/bahwa guru tentang mati adalah orang mati/bahwa guru tentang hidup adalah orang hidup/cara meyakini yang sejati/adalah dengan jalan menemuinya'

Pada dasarnya, manusia bisa belajar tentang konsep kematian kepada orang yang sudah meninggal dunia terlebih dahulu. Entah disadari entah tidak, sesungguhnya setiap hari manusia sudah diberikan gambaran oleh Allah bahwa jarak antara kehidupan dan kematian sangatlah dekat. Setiap pagi diibaratkan sebagai hari kelahiran, sedangkan setiap malam adalah malam kematian. Hal ini dikarenakan setiap malam ketika seseorang tidur, sama artinya dengan mengalami kematian sesaat sampai seorang itu bangun kembali (Hidayat, 2005:4$5)$.

Orang yang sudah tiba masa kematiannya tidak akan bisa menghindarinya. Ia akan pergi meninggalkan dunia tanpa membawa apapun, kecuali hanya amal ibadah yang menemaninya Orang yang meninggal dunia tidak akan bisa hidup di dunia lagi, mereka sudah memiliki alam yang berbeda. Oleh karena itu, manusia yang masih Allah berikan kesempatan untuk hidup di dunia seyogyanya tidak terlena dengan gemerlap dunia dan lebih memilih untuk mempersiapkan kematian dengan meningkatkan amalanamalan yang kelak akan menemaninya di akhirat nanti.

Penegasan tentang kematian ini diulang kembali dalam pupuh Pucung bait kelima sebagai berikut.

(13) Yèn wong putus sandhining Hyang tan kalimput/sampurnaning pêjah/tan sudi mamêt puniki/yèn wong mati gurune janma pralaya// (PU-VIII/B15)

'Jika orang benar-benar menguasai rahasia tentang Tuhan tentu tidak akan salah/cara mati yang sempurna/tidak akan sudi menuruti cara seperti itu/jika ingin belajar ilmu 
Mila Indah Rahmawati, dkk/ Sutasoma 9 (1) (2021)

mati yang sempurna sebagai gurunya adalah orang mati itu sendiri'

Kematian adalah suatu keniscayaan. Untuk memahami konsep kematian, perlu belajar dari orang yang sudah meninggal. Hal itu dinyatakan Raden Panji Natarata dalam larik yèn wong mati gurune janma pralaya 'jika ingin belajar ilmu mati yang sempurna gurunya adalah orang mati itu sendiri'.

Kematian bukanlah sebuah akhir, tetapi sebuah awal kehidupan dan pertanggungjawaban di akhirat. Orang yang sudah meninggal terlepas dari kehidupan dunia, sama sekali tidak membawa harta benda. Dengan begitu seyogyanya manusia lebih giat melakukan amal saleh, menjauhkan diri dari perbuatan tercela, dan melakukan taubat sehingga dapat kembali dalam keadaan yang sebaik-baiknya (suci). Kesucian inilah yang dapat mengantarkan manusia bertemu dengan Yang Maha Suci, yaitu Allah Subhanahu Wa Ta'ala.

\section{SIMPULAN}

Inti dari penelitian ini adalah menguraikan adanya penyimpangan akidah yang dialami oleh Raden Panji Natarata selama masa pengembaraannya dalam menemukan hakikat kehidupan. Di samping itu, Raden Panji Natarata juga memberikan penjelasan dan penegasan terhadap ajaran-ajaran menyesatkan yang ia dapatkan dari para guru, ulama, maupun sarjana yang ia temui selama masa pengembaraannya dengan berdasarkan Al-Qur'an dan hadits atau sabda Nabi.

Dalam memaknai konsep wujud Allah, Raden Panji Natarata berpendapat bahwa secara fisik manusia tidak dapat dikatakan sebagai Tuhan karena ketika makhluk didefinisikan sebagai wujud materiel, ia tidak akan dapat bersatu dengan Tuhan. Walaupun di sisi lain hidup manusia mengandung Dzat atau sifat-sifat baik yang merupakan perwujudan dari sifat Tuhan. Intinya, Tuhan (Allah) adalah Dzat yang tidak dapat dijangkau oleh angan-angan dan manusia. Allah tetap bersifat transenden terhadap alam semesta dan seisinya (Karomi, 2013:289). Namun demikian, aspek keilahian Allah dapat terlihat selama manusia mampu menyucikan hatinya dari pengaruh nafsu dan bermawas diri.

Adapun asal manusia diciptakan dari Nabi Adam dan di kehidupan ini manusia mengemban tugas untuk beribadah kepada Allah sebagai bekal setelah kematian nanti. Dari kematian itulah manusia perlu memahami bahwa kematian bukanlah akhir dari segala yang ada, tetapi sebaliknya, kematian adalah awal dari kehidupan yang baru. Satu-satunya cara yang dapat manusia lakukan jika ingin belajar tentang kematian adalah dari orang mati itu sendiri.

Terakhir, penelitian ini diharapkan mampu memberikan sumbangsih terhadap khasanah kesusastraan Indonesia, khususnya karya sastra Jawa yang bernuansa tasawuf. Selain itu, besar harapan peneliti agar karya sastra berjudul Serat Bayanolah karya Raden Panji Natarata ini juga dapat diteliti melalui kajian interdisipliner ilmu lain, misalnya ditinjau dari sisi semantik, pragmatik, dan sebagainya. 
Mila Indah Rahmawati, dkk/ Sutasoma 9 (1) (2021)

\section{DAFTAR PUSTAKA}

El Firdausy, S. W. (2017). Hakikat Tuhan: Kajian Pemikiran Islam dalam Falsafah Jawa. SHAHIH: Journal of Islamicate Multidisciplinary, 2 (1), 97. https://doi.org/10.22515/shahih.v2i1. 684

Hidayat, K. (2005). Psikologi Kematian: Mengubah Ketakutan Menjadi Optimisme. Bandung: PT Mizan Publika.

Karim, A. (2015). Makna kematian dalam perspektif tasawuf. Esoterik, 1(1), 2146.

Marzuki. (n.d.). Tradisi dan Budaya Masyarakat Jawa dalam Perspektif Islam.

Natarata, R. P. (2010). Serat Bayanolah. Yayasan Sastra Lestari. https://www.sastra.org/katalog/judul ?ti_id=129

Rahman, A. A., \& Khoirul Hodayah. (2011). Islam dan Budaya Masyarakat Yogyakarta Ditinjau dari Perspektif Sejarah. El-Harakah, 13(1), 46-59. https://doi.org/10.18860/el.v0i0.2019

Rubaidi. (2019). Javanese Islam; A Blend of Javanese Culture and Islamic Mysticism Viewed from Post-Colonial Perspective. El-Harakah, 21(1), 19-36. https://doi.org/http://dx.doi.org/10.1 8860/el.v21i1.6066

Saddhono, K., \& Pramestuti, D. (2018). Study of Religious Values Based on Javanese Local Wisdom. El-HARAKAH, 20(1), $15-32$.

https://doi.org/10.18860/el.v20i1.472 4

Sahal Akhmad. (2015). Islam Nusantara dari Ushul Fiqh Hingga Paham Kebangsaan (MunawirAziz (Ed.)). Bandung: Mizan.

Saputro, I. (2016). Konsep Tauhid Menurut Abdul Karim Amrullah dan Implikasinya terhadap Tujuan Pendidikan Islam. At Ta'Dib, 11(2). https://doi.org/10.21111/attadib.v11i2.779

Simuh. (1988). Mistik Islam Kejawen Raden Ngabehi Ranggawarsita. Depok: UI Press.

Soehadha, M. (2016). Tauhid Budaya Strategi Sinergitas Islam dan Budaya Lokal dalam Perspektif Antropologi Islam. 13, 15-32.
Kemenag RI. (2016). Al-Mahir Mushaf dan terjemah Tajwid Warna. Sukoharjo: Madina Qur'an.

Sudaryanto. (1993). Metode dan Teknik Analisis Bahasa. Jakarta: SERI ILDEP.

Susanto, E. (2016). Tembhang Macapat dalam Tradisi Islami Masyarakat Madura. Purwokerto: Ibda' Jurnal Kebudayaan Islam, 14(2).

Suteja, Ibnu Pakar. (2016). Tasawuf di Nusantara Tadarus Tasawuf dan Tarekat. Cirebon: CV Aksarasatu.

Utomo Imam Budi. (2007). Konsepsi Tasawuf dalam Beberapa Karya Raden Ngabehi Ronggawarsita. Litera, 6(1), 33-46.

Utomo Iman Budi. (2007). Konsepsi Tasawuf dalam Beberapa Karya Raden Ngabehi Ranggawarsita. Litera, 6(1).

Zainuddin. (2013). Mengenal Filsuf Muslim dan Pemikiran Filsafat Ketuhanan. UIN Malang. https://www.uinmalang.ac.id/r/1311 01/mengenal-filosuf-muslim-danpemikirannya-a-filsafat-ketuhanan.html 